\title{
COMUNICAÇÃO E CONSUMO: SOBRE A PRODUÇÃO DE MODOS DE VIDA NO AIRBNB
}

\section{Communication and consumption: on the production of modes of existence on Airbnb}

Comunicación y consumo: la producción de modos de vida en Airbnb

\author{
Ramon Bezerra Costa \\ Universidade Federal do Maranhão, Maranhão, Brasil. \\ Professor do Departamento de Comunicação Social da Universidade Federal do Maranhão. Mestre e doutor \\ pelo Programa de Pós-Graduação em Comunicação da Universidade do Estado do Rio de Janeiro. \\ E-mail: ramonbzc@gmail.com
}

RESUMO Este artigo reflete sobre o Airbnb, um site que permite alugar a própria residência, estando ou não nela, para desconhecidos, e evidencia lógicas de organização que parecem distender as fronteiras entre as vidas pública e privada, e conformar singulares processos de construção da confiança entre desconhecidos. O fenômeno será abordado na perspectiva da comunicação e do consumo, aqui entendidos como processo de vinculação social e produção de modos de vida, respectivamente.

PALAVRAS-CHAVE Airbnb, Consumo, Vínculo Social, Produção de Subjetividade.

\begin{abstract}
This paper reflects upon Airbnb, a website that allows one to rent their own residence to strangers, whether living there or not, thus pointing to logics of organization that seem to blur the lines between private and public life, conforming unique processes of construction of trust among strangers. This phenomenon will be addressed through the perspectives of communication and consumption, understood here as process of social bonds and production of modes of existence, respectively.
\end{abstract}

KEYWORDS Airbnb, Consumption, Social bonds, Production of subjectivity.

RESUMEN En este trabajo discutimos el sitio Airbnb, que permite a uno alquilar su propria casa a desconocidos, esté el dueño en ella o no, con la finalidad de evidenciar lógicas de organización que parecen distender las fronteras entre lo público y lo privado y conformar singulares procesos de construcción de confianza entre desconocidos. El fenómeno se abordará bajo la perspectiva de la comunicación y del consumo, entendidos como procesos de vínculo social y de producción de modos de vida, respectivamente.

PALABRAS CLAVE Airbnb, Consumo, Vínculo Social, Producción de Subjetividad. 


\section{INTRODUCÃO}

Em 2007, conforme lembra Joe Gebbia (2012), dois amigos que dividiam o apartamento na cidade de São Francisco (Califórnia, EUA), diante de um grande evento em sua cidade que estava ocupando boa parte da rede hoteleira, pensaram em colocar um colchão de ar na sala, oferecer café da manhã (Airbed and breakfast, por isso a sigla Airbnb) e divulgar o aluguel por temporada para participantes do evento. Isso ajudaria a pagar o aluguel. A experiência foi positiva, ficaram amigos dos hóspedes e, depois disso, em 2008, criaram um site para que outras pessoas pudessem oferecer um local extra em casa, ou a casa interia, e ganhar dinheiro com isso.

Como era de se esperar, no início da empresa, os possíveis investidores achavam que ninguém aceitaria abrir e alugar a própria casa. Afinal, soa estranho sair para trabalhar, viajar e deixar a casa com objetos de valor sentimental e material, às vezes conseguidos com esforço, com desconhecidos, ou simplesmente ir dormir com um estranho no quarto ao lado. Contrariando as expectativas iniciais, após oito anos, o Airbnb é uma empresa com valor de mercado em US\$ 25 bilhões (Borneli, 2015) e escritórios em diversas cidades do mundo para administrar milhões de acomodações em mais de 34 mil cidades de 190 países usadas por mais de sessenta milhões de pessoas (Airbnb, 201-?).

Além de apartamentos e casas, inteiros ou quartos, por meio do Airbnb é possível alugar castelos, ilhas, cavernas, iglus, casas na árvore, barcos. Os preços são tão diversos quanto as possibilidades de acomodação, podendo ser mais barato que um albergue ou mais dispendioso que um hotel de luxo, variando também pela localidade, transportes e outras facilidades, como qualquer serviço.

A empresa funciona como uma "vitrine" dos lugares para alugar e como "mediadora" das relações, ganhando uma porcentagem sobre cada transação realizada em seu site. Assim, o Airbnb se apresenta com a função de conectar viajantes, que estão em busca de uma acomodação barata e/ou do que chamam de "uma experiência única", e pessoas com algum espaço sobrando para alugar.

A partir de estruturas já existentes, em geral lugares ociosos e baseados nas redes digitais de comunicação, o Airbnb popularizou ${ }^{1}$ um modelo de negócios que ainda não é previsto nas legislações. Além dos escritórios e seus funcionários, que lugar teriam os anfitriões nesse modelo de negócios, uma vez que oferecem a "matéria-prima” do serviço de hospitalidade? Como são construídas as relações entre os sujeitos? Como confiar em desconhecidos a ponto de deixá-los ficar na própria casa e compartilhar o ambiente doméstico?

Essas são algumas das questões que a experiência do Airbnb desperta e que serão discutidas neste trabalho, na perspectiva da comunicação e do consumo. Fala-se em comunicação na esteira do pensamento de Sodré (2001), para quem o objeto de estudo da comunicação é a vinculação social. Sendo assim, pensar o Airbnb nessa perspectiva é refletir sobre como as pessoas se relacionam de maneira a configurar essa experiência e o que isso sugere. No que diz respeito ao consumo, compreendendo-o como

1. Antes do Airbnb já existiam serviços parecidos, como o TrocaCasa.com, que permite a troca de hospedagem entre viajantes. Contudo, pode-se considerar que foi a partir do Airbnb que esses hábitos se popularizaram e se converteram em um modelo de negócio com rentabilidade significativa. 
diferentes maneiras de se relacionar com produtos e serviços, segue-se a trilha de Douglas e Isherwood (2013), que percebem o consumo como processo que estrutura relações sociais e produz modos de vida. Dessa forma, trabalha-se com a ideia de que abordar as relações de consumo é tratar dos "processos de produção social de subjetividade" que configuram a experiência do Airbnb. Fala-se em "subjetividade" a partir de Guattari, entendendo-a como "o conjunto das condições que torna possível que instâncias individuais e/ou coletivas estejam em posição de emergir como território existencial autorreferencial” (Guattari, 1992, p. 19).

Nesse sentido, esses processos de produção social de subjetividade podem ser entendidos como a configuração de conjuntos de referenciais que orientam nossa percepção sobre a vida e ação no mundo, constituindo assim modos de vida.

Diante desses pressupostos, este artigo reflete sobre a experiência do Airbnb para discutir as lógicas de funcionamento que produzem as realidades nas quais vivem os sujeitos e que são a expressão de crenças e valores, perpassando diversos campos, como o econômico e a vida pessoal; evidenciando, assim, a produção de modos de vida implicada nessa experiência.

\section{ORGANIZAÇÃO}

O primeiro passo aos interessados em oferecer ou alugar um espaço no Airbnb é criar um perfil com nome, foto, e-mail e endereço. O site também oferece ferramentas para confirmar a identidade (visando a construção da confiança) por meio do perfil nas chamadas redes sociais (como o Facebook, por exemplo) e documentos. Para os interessados em alugar seu espaço, é necessário também descrever o local, colocar fotos, preços, datas disponíveis e eventuais taxas, como limpeza, por exemplo. Para quem for procurar um lugar, o caminho é escrever a cidade de destino, as datas de chegada e partida e o número de hóspedes para encontrar as opções disponíveis. Após isso, pode-se escolher o bairro e o tipo de imóvel - várias cidades do mundo possuem guias de bairro com fotos e características do local feitas por fotógrafos e outros profissionais contratados pelo Airbnb.

Ao buscar um lugar, observar as referências dos anfitriões e hóspedes ${ }^{2}$ é fundamental, são elas que permitem, por exemplo, ao hóspede ter informações que não sejam apenas as opiniões autodeclaradas pelo anfitrião. Durante a busca, é possível criar uma lista com os locais favoritos e trocar mensagens com os anfitriões para tirar dúvidas. Após decidir onde ficar, o hóspede realiza a reserva, o anfitrião aceita ou não o pedido e o pagamento pode ser realizado pelo site e com o cartão de crédito. O valor da reserva só é repassado ao anfitrião após a chegada do hóspede - neste momento o Airbnb retira sua porcentagem. Além do site, todo esse procedimento também pode ser realizado por meio de aplicativo para smartphone.

Para Soares (2014), gerente de mercado do Airbnb no Rio de Janeiro, a empresa parte da necessidade de uma economia que seja sustentável, que invista no desenvolvimento de interações (econômicas e humanas) mais equilibradas, tentando equiparar o que todas as partes ganham. Independente de uma análise que permita afirmar se tais objetivos são

2. Comentários deixados pelos hóspedes e anfitriões, uns aos outros, após cada estadia. Em geral, tanto características do lugar quanto impressões pessoais sobre o outro compõem essas referências. 
concretizados ou não, é notório que os lucros da empresa são maiores que os dos anfitriões. Nesse sentido, talvez o Airbnb não apresente diferença de outros modelos de negócios, mas o singular parece estar nas relações mobilizadas para sustentar esse modelo.

Grande parte dos funcionários do Airbnb são também anfitriões e hóspedes que utilizam a plataforma. A empresa, inclusive, incentiva isso: cada empregado ganha um voucher e dias de folga a cada três meses para viajar para onde quiser (Soares, 2014). Assim, o perfil dos funcionários é também o dos usuários e/ou anfitriões, ou seja, vidas pessoal e profissional estão juntas, e as características de ambas se cruzam. Se um funcionário/ hóspede deixou um lugar sujo após sua estadia ou causou qualquer outro problema, isso certamente constará em seu perfil e interferirá em seu trabalho, por exemplo.

É uma relação diferente da existente em uma rede hoteleira que oferece descontos para seus funcionários se hospedarem em seus hotéis durante suas viagens de férias, porque uma descrição de como foi a estadia não ficará exposta no "perfil do hóspede ou do hotel" como forma de "referência”, que além do mais é uma instituição, e não pessoa física, e não se trata da residência (ambiente privado) do outro.

Além disso, ainda que o funcionário do Airbnb necessite cumprir apenas um número determinado de horas de trabalho no escritório, é como se sua função de profissional não se "desligasse", nem mesmo em suas viagens de férias. Isso sem contar o fato de poderem trabalhar a distância, respondendo mensagens e administrando o site a qualquer hora. A possibilidade de levar o cachorro para o escritório e brincar com ele entre uma tarefa e outra talvez também ilustre essa combinação entre trabalho e vida privada (Soares, 2014).

Esse funcionamento lembra uma das características do que Deleuze (2010) chamou de "sociedade de controle", na qual nunca se para de trabalhar, nunca se termina nada. Essa junção de vida pessoal e profissional faz parte de processos de produção social de subjetividade que moldam a forma como os sujeitos vivem, alterando suas relações com o espaço e o tempo, com a família, o lazer e mesmo sua visão de mundo. Essa experiência vale também para os anfitriões, que além dos seus outros trabalhos administram hóspedes no tempo que sobra de sua rotina diária, atuando entre a vida pessoal do ambiente doméstico, com suas idiossincrasias, e a formalização de um anfitrião do Airbnb que oferece um serviço.

Esse modo de funcionamento é característico do capitalismo atual. Conforme encontramos em vários estudos (Hardt; Negri, 2005, 2010; Foucault, 2008; Deleuze, 2010, entre outros), as mudanças socioeconômicas das últimas décadas têm transformado os modos de produção, de construção de valor e a natureza do trabalho. Atualmente, esses processos têm íntima relação com as tecnologias digitais de comunicação. Observa-se um modelo no qual conhecimento e informação (bens imateriais e relacionais) seriam as principais fontes de valor. Para Negri (2003), o trabalho imaterial, característico dessa expressão do capitalismo, pode ser entendido como "o conjunto das atividades intelectuais, comunicativas, afetivas”. É importante enfatizar, segundo afirmação de Hardt e Negri (2005), que embora os trabalhadores envolvidos unicamente na produção imaterial sejam uma minoria global, a questão é que as características dessa forma de produção tendem a transformar as outras formas de trabalho e toda a sociedade. 
Não é mais apenas o patrão capitalista que tem a propriedade dos meios de produção e cede aos empregados determinado período de tempo para produzir um produto específico. É possível existir modelos, como no caso do Airbnb, no qual um sujeito, em sua casa (mudança de ambiente), produz em seu computador (sua propriedade), no tempo que julgar melhor e se organiza em um site com a função de administrar os fluxos e funcionar como vitrine. No entanto, o Airbnb não se resume ao aspecto imaterial.

Os funcionários, distribuídos nos escritórios, têm como função administrar as reservas, gerir a segurança e todas as funções do site, isto é, promover um bom espaço de relação entre anfitriões e hóspedes. De certa forma, talvez seja possível considerar que o Airbnb trabalha com um "produto imaterial", tendo em vista que a empresa não é proprietária dos locais disponíveis para alugar e sua função básica é gerir fluxos, assim como empresas como o Facebook ou o Google. No entanto, as vagas para alugar disponíveis no site são locais físicos, embora de propriedade de outras pessoas que resolveram participar da plataforma. É uma empresa que administra fluxos imateriais, mas não para fins imateriais. Além disso, não parece plausível resumir a empresa aos funcionários dos escritórios, já que a “matéria-prima”, onde o Airbnb acontece, está entre os muitos desconhecidos ao redor do mundo.

No que diz respeito aos anfitriões, observa-se a geração de renda a partir de objetos que são suas propriedades (imóvel, móveis, utensílios domésticos). Nesse modelo, quem aluga ganha dinheiro extra com algo que já tem e não usa, ou que pode compartilhar; monetizando seus espaços ociosos e disponibilizando a uma plateia de milhões de pessoas pelo Airbnb.

Seria possível falar em exploração dos proprietários do Airbnb sobre as pessoas que colocam seus lugares à disposição, tendo em vista que a empresa está milionária e os anfitriões, no máximo, incrementam sua renda? Alguns dos motivos que possibilitam a existência do Airbnb é o desejo de participação e a disposição dos anfitriões a fornecerem sua casa, mas sem a plataforma não seria possível o incremento da renda. Até existem outros sites como o Airbnb pelo mundo, mas ainda incipientes e funcionando de maneira semelhante.

Assim, de alguma maneira, os anfitriões, que em certos momentos também podem ser hóspedes, não fariam parte da empresa? Ou seriam apenas usuários? Mas, usuários que oferecem a "matéria” que permite a existência do serviço? Obviamente, não integram formalmente a empresa, menos ainda participam dos lucros, até porque o Airbnb possui uma estrutura centralizada em escritórios distribuídos estrategicamente para administrar as reservas, mas esses sujeitos ocupam um lugar curioso que pode expressar singulares formas de vinculação. Talvez, devido a essa relação complexa, o Airbnb prefira se ver como uma "comunidade”, ao invés de uma empresa, como diz Soares (2014), eles nem se consideram "funcionários", mas como parte de uma "comunidade" que trabalha na organização da dinâmica.

Isso pode parecer um mero recurso retórico, mas talvez indique algo. O Airbnb parece um tipo de "empresa ampliada” que funciona a partir de singulares tipos de vinculação. Parece ser preciso existir uma espécie de "sentimento de pertença” e a predisposição das pessoas em participar. É necessário também confiar no outro a ponto de abrir a própria casa a um estranho. Parece mobilizar, assim, um investimento pessoal maior para uma relação de consumo pouco usual - isso será discutido no próximo item. 
Diante disso, o Airbnb parece apresentar traços de um modelo centralizador, baseado na figura de proprietários e investidores, que acumulam lucros; ao mesmo tempo em que essa experiência se sustenta na gestão de fluxos imateriais que, por sua vez, parte da cooperação de sujeitos dispersos que oferecem suas casas e a disposição de se relacionar e viver essa experiência. O mais curioso no Airbnb parece ser exatamente a disposição das pessoas em experimentar esse modo de geração de renda e produção de modos de vida.

\section{VÍNCULOS}

Conforme foi sugerido, a empresa existe na medida em que as pessoas escolhem participar, colocando suas residências à disposição e/ou usando o serviço. Ainda que em alguns casos a renda gerada por meio do Airbnb possa ser importante no orçamento mensal, em geral os anfitriões possuem outras fontes de renda e o que se ganha por meio do Airbnb é um recurso extra. Assim, por mais que o rendimento financeiro seja uma motivação, não parece suficiente para explicar a disposição em participar do Airbnb, o que parece sugerir outras relações.

Em 2014, o Airbnb lançou uma nova logomarca, chamada de Bélo, que pretende simbolizar um mundo onde "as portas estão sempre abertas" (Blog Airbnb, 2014) e indica o interesse da empresa em construir um "sentimento de pertença" ao fazer com que os membros se sintam "acolhidos" e "seguros" em qualquer lugar do mundo, desde que estejam usando o serviço.

Contudo, por onde passa a construção desse "sentimento de pertença"? Certamente, a construção desse sentimento passa pela plataforma, mas também pelas propagandas, os e-mails em tom pessoal e a sempre presente ideia de que o Airbnb não é uma empresa, mas uma comunidade que permite experiências únicas e pessoais entre os sujeitos. Como já foi dito, existem outras plataformas que oferecem serviços parecidos com o do Airbnb, mas menos conhecidas e sem essas estratégias de “aproximação do público”. Então, sem dúvida, a construção desse "sentimento de pertença” passa por esses fatores, mas também por certa "configuração dos sujeitos”, o que interessa neste trabalho.

Usar o Airbnb parece sugerir uma predisposição dos sujeitos a uma relação de proximidade com o outro. O hóspede troca a impessoalidade, padronização e alguns serviços de um hotel, como ter a roupa lavada e passada, pela casa de um desconhecido, onde talvez não tenha esses serviços e, se tiver, ele próprio precisará fazer. O maior trabalho e a possível falta de privacidade (caso alugue só um quarto) não se justificam apenas pela economia financeira, porque nem sempre a hospedagem no Airbnb é mais barata que em um hotel/albergue (algumas vezes é bem superior). $O$ fato é que são serviços e funcionamentos bem diferentes. Assim, quem opta pelo Airbnb está aderindo a um modo de estar no mundo, perpassado, talvez, por uma forma de relação com o outro menos instrumental.

Enquanto em um hotel parece que se lida com "funções" (camareira, recepcionista), na experiência do Airbnb talvez seja com "sujeitos", que podem até desempenhar as funções de um hotel, mas que não se resumem a ela e escapam da padronização. Em geral, os anfitriões orientam os hóspedes sobre como se movimentar na cidade, às vezes levam para passear e apresentam a localidade, o que poderia ser encontrado na recepção de um hotel ou em uma agência de turismo, mas com outro "tom". No hotel, os funcionários são pagos por aquele serviço, no Airbnb também, de certa maneira, e quanto mais gentis forem, melhores referências receberão e 
mais hóspedes poderão vir e, consequentemente, maior rendimento; mas ainda assim estão ali enquanto sujeitos, e não como função, carregam e deixam transparecer seus valores, história de vida e modos de viver.

Ainda que o anfitrião não esteja interessado em conhecer e interagir com o hóspede, e vice-versa, ao abrir sua casa, ambos convivem; ou mesmo quando se encontram apenas para entregar as chaves, um desconhecido "usa suas louças, seu banheiro e vive em sua residência". Isso parece sugerir um tipo singular de relação, de existir enquanto sujeito. A motivação pode até ser apenas ganhar dinheiro, no entanto, ela se dá por meio de uma relação singular com o outro e de troca, em algum nível.

Ao estudar o que se pode chamar de uma "ontologia da relação", Buber (2001) fala de duas atitudes nas quais se baseariam as relações com o outro: "Eu-Tu", fundada em uma reciprocidade, na entrega e na abertura ao outro, momento esse que não é dotado de um sentido cognitivo ou mesmo formal, apenas vive-se; e "Eu-Isso", quando a relação possui um caráter instrumental, funcional, sem entrega e abertura ao outro. Parece ser plausível sugerir que a relação no Airbnb se aproxima do que Buber (2001) chama de "Eu-Tu", enquanto em um hotel estaria mais próxima do "Eu-Isso" - ainda que as relações transitem entre essas duas atitudes.

Nos comentários escritos pelos hóspedes nos perfis dos anfitriões, e vice-versa, há frequentes referências às características pessoais de ambos, em alguns casos isso prevalece sobre as características físicas do lugar. Mesmo quando se encontram apenas para entregar as chaves, essa relação pode ser marcada por trocas de mensagens sobre como as pessoas são, o que irão fazer (essas perguntas fazem parte das estratégias de construção da confiança utilizadas), entre outras perguntas desnecessárias em um hotel, mas que não deixam de aproximar os sujeitos e, talvez, criar outro tipo de experiência de vinculação. Isso não diz respeito a ficar amigo e passar a manter contato com os antigos hóspedes, ainda que alguns façam isso, mas a se comportar de outra forma.

Assim, participar do Airbnb parece requerer certo tipo de experiência de vinculação social dos sujeitos, isto é, certo tipo de experiência de comunicação. Conforme propõe Sodré (2007), comunicar é instaurar o comum, mas não como ente, e sim como vinculação:

Como um nada constitutivo, pois o vínculo é sem substância física ou institucional, é pura abertura na linguagem. O sujeito que se comunica é o mesmo ser como "entre", logo, uma interioridade destinada a uma exterioridade, o outro. [...] Para vincular-se, é preciso que cada um perca a si mesmo, que lhe falte o absoluto domínio da subjetividade e da identidade em função da abertura para o outro. (Sodré, 2007, p. 21)

Assim, o comum é uma espécie de "vazio" que pode ser visto como um espaço relacional, de vir a ser, nele se constroem os vínculos para os quais a confiança parece fundamental, pois sem ela talvez se torne difícil (ou impossível) a abertura ao outro. Esse comum não é predeterminado, é construído na relação.

Parece necessário encarar a experiência do Airbnb nesse nível, que requer a constituição de um comum entre os sujeitos para que possam construir a confiança, estabelecer uma vinculação e acontecer a experiência. Afinal, sem confiar, como abrir a porta de casa a alguém? Richard Sennett (2012a), a partir da observação de como se dão as relações de trabalho em instituições, considera que a confiança perde as condições para existir na medida em que diminuem as relações de 
longo prazo, porque os sujeitos não teriam tempo para se vincular. Porém, na experiência do Airbnb, parece que se observa outro processo de construção da confiança, quase instantâneo.

No Airbnb, a construção da confiança passa pelas referências, mensagens trocadas pelo site, entre outras estratégias que não foram o foco deste trabalho, mas também por uma espécie de predisposição dos sujeitos para esse tipo de relação. De onde viria essa predisposição? Embora não seja possível ensaiar uma resposta definitiva, parece plausível refletir a partir de Buber (2001), que considera que não existe sujeito senão em relação, por isso o vínculo é tão importante. Para esse filósofo, somente relações baseadas na atitude "Eu-Tu" são capazes de constituir o sujeito, uma vez que seriam dotadas de reciprocidade, de entrega e abertura ao outro, e é nesse "encontro" que há uma espécie de arrebatamento que mobiliza e constitui os sujeitos. No entanto, conforme defende Sennett (2012b, p. 19), “a sociedade moderna está 'desabilitando' as pessoas da prática da cooperação” com o outro, afastando os sujeitos e fragmentando as relações, seja por conta de desigualdades econômicas e sociais ou configurações na esfera do trabalho. Assim, se a cooperação com o outro e a vinculação para a construção de um comum são tão importantes, e se foram perdidas devido às formas de funcionamento das sociedades atuais, que parecem se aproximar da atitude "EuIsso” (Buber, 2001), buscá-las parece compreensível. Dessa maneira, a predisposição dos sujeitos em participar do Airbnb talvez tenha relação com a necessidade do vínculo social.

O Airbnb tem sido processado em algumas cidades do mundo por ser um modelo de negócios ainda não regulado e que não paga impostos. Isso gerou mobilizações em algumas cidades. É interessante notar que algumas mobilizações foram iniciadas não pelos funcionários do site, mas por anfitriões, como na cidade de Nova Iorque (EUA) (Peers, 201-?). Alguns podiam estar defendendo o acréscimo mensal na renda, outros o espaço que permite fazer amigos e conhecer outras culturas ao mesmo tempo em que se ganha dinheiro, entre outras motivações; o fato é que talvez seja possível considerar que estavam defendendo um determinado processo que os constitui como sujeitos.

\section{CONSIDERAÇÕES FINAIS}

A ideia de criar um site como o Airbnb, facilitada por uma infraestrutura tecnológica acessível (computadores/internet), que reduz o custo da transação e aumenta sua escala, aliada a um momento de facilitação/ barateamento das condições de transporte e comunicação, encontra ressonância em sujeitos já sensibilizados para experiências de trabalho que unam vida pessoal e profissional, capitalizando sua vida privada, e predispostos a uma singular forma de vinculação social e a confiar em mecanismos baseados nos rastros online uns dos outros. Esses são alguns dos elementos que fazem parte da construção dos conjuntos de referenciais que orientam as percepções desses sujeitos sobre o mundo e constituem seus modos de vida, isto é, os processos de produção social de subjetividade.

Apesar do singular modelo de negócios do Airbnb, mantém-se uma gestão centralizada e a figura dos donos, acionistas, investidores e a obtenção de lucros. No entanto, o que há de mais curioso são as relações criadas que sustentam esse modelo, caracterizadas por experiências que evidenciam a possibilidade dos sujeitos confiarem uns nos outros e se 
vincularem, isto é, uma predisposição de se relacionar com o outro como sujeito, e não como função.

Compartilhar parece que não é mais só uma prática que acontece entre amigos e conhecidos em quem se confia por conta de relações anteriores. Parece positivo ganhar dinheiro e se aproximar do outro ao mesmo tempo; e não só com colegas de trabalho e/ou em um lugar específico e impessoal, mas na própria casa.

Longe de trazer respostas e explicações definitivas, a proposta deste trabalho, a partir de uma perspectiva exploratória, foi apenas levantar caminhos para reflexão sobre um significativo fenômeno para o campo dos estudos da comunicação e do consumo, que parece mobilizar singulares formas dos sujeitos se vincularem socialmente, constituíremse como sujeitos e arquitetarem modos de vida ao se relacionarem com um serviço de hospitalidade.

\section{REFERÊNCIAS}

AIRBNB. Quem somos. Airbnb, Rio de Janeiro, 201-?. Disponível em: http://bit.ly/1XuM90Y. Acesso em: 25 abr. 2016.

BLOG AIRBNB. O mundo é a tua casa. Airbnb, Rio de janeiro, 16 jul. 2014. Disponível em: http://bit.ly/2mJ8Nul. Acesso em: 27 mar. 2016.

BORNELI, J. Airbnb recebe novo aporte e se iguala a Petrobras e Vale em valor de mercado. In: StartSe, Minas Gerais, 11 dez. 2015. Disponível em: http://bit.ly/2n9NMnV. Acesso em: 25 abr. 2016

BUBER, M. Eu e Tu. São Paulo: Centauro, 2001.

DELEUZE, G. Conversações. São Paulo: Editora 34, 2010.

DOUGLAS, M.; ISHERWOOD, B. O mundo dos bens: para uma antropologia do consumo. Rio de Janeiro: UFRJ, 2013.

FOUCAULT, M. Nascimento da Biopolítica. São Paulo: Martins Fontes, 2008.

KEYNOTE Joe Gebbia at TNW2012. In: YouTube. Amsterdam: TNW Conference 2012. Vídeo (22min38s). Disponível em: http://bit.ly/2ejpVmY. Acesso em: 25 abr. 2016.

GUATTARI, F. Caosmose: um novo paradigma estético. Rio de janeiro: Editora 34, 1992.

HARDT, M.; NEGRI, A. Multidão: guerra e democracia na era do império. Rio de Janeiro: Record, 2005

Império. Rio de Janeiro: Record, 2010.

NEGRI, A. Cinco Lições sobre Império. Rio de Janeiro: DP\&A, 2003.

PEERS. Save Airbnb in New York: legalize sharing. Peers, New York, 201-?. Disponível em: http://bit.ly/2dIMMx8. Acesso em: 25 abr. 2016.

SENNETT, R. A corrosão do caráter: consequências pessoais do trabalho no novo capitalismo. Rio de Janeiro: Record, 2012a.

2012b. Juntos: os rituais, os prazeres e a política da cooperação. Rio de Janeiro: Record

SOARES, S. [Entrevista]. Airbnb: uma comunidade de viajantes. In: Templo, Rio de Janeiro, 21 ago. 2014. Disponível em: <http://www.templo.co/blog/airbnb-uma-comunidade-de-viajantes/>. Acesso em: 16 jul. 2014.

SODRÉ, M. Sobre a episteme comunicacional. In: Revista Matrizes, São Paulo, v. 1, n. 1, p. 15-26, 2007.

[Entrevista]. Objeto da comunicação é a vinculação social. In: PCLA: Revista Científica Digital, v. 3, n. 1, out./nov./dez. 2001. Entrevistadora: Desirée Rabelo. Disponível em: <http://bit.ly/2nVmW3n>. Acesso em: 25 abr. 2016. 